\title{
Prognostic values of GMPS, PR, CD40, and p21 in ovarian cancer
}

\author{
Ping Wang ${ }^{1}$, Zengli Zhang ${ }^{2}$, Yujie Ma ${ }^{1}$ ， Jun Lu ${ }^{1}$ ， Hu Zhao ${ }^{1}$, Shuiliang Wang ${ }^{1}$ ， Jianming Tan ${ }^{\text {Corresp.., }}{ }^{1,3}$, \\ Bingyan Li Corresp. 2 \\ ${ }^{1}$ Fujian Key Laboratory of Transplant Biology, Fuzhou General Hospital, Fuzhou, Fujian, China \\ 2 Department of Toxicology, School of Public Health, Soochow University, Suzhou, Jiangsu, China \\ 3 Fujian Hongyi Health Institute, Fuzhou, Fujian, China \\ Corresponding Authors: Jianming Tan, Bingyan Li \\ Email address: tanjm156@xmu.edu.cn, bingyanli@suda.edu.cn
}

Early detection and prediction of prognosis and treatment responses are all the keys in improving survival of ovarian cancer patients. This study profiled an ovarian cancer progression model to identify prognostic biomarkers for ovarian cancer patients. Mouse ovarian surface epithelial cells (MOSECS) can undergo spontaneous malignant transformation in vitro cell culture. These were used as a model of ovarian cancer progression for alterations in gene expression and signaling detected using the Illumina HiSeq2000 Next-Generation Sequencing platform and bioinformatical analyses. The differential expression of four selected genes was identified using the gene expression profiling interaction analysis (http://gepia.cancer-pku.cn/) and then associated with survival in ovarian cancer patients using the Cancer Genome Atlas dataset and the online Kaplan-Meier Plotter (www.kmplot.com) data. The data showed 263 aberrantly expressed genes, including 182 up-regulated and 81 down-regulated genes between the early and late stages of tumor progression in MOSECs. The bioinformatic data revealed four genes [i.e., guanosine 5'-monophosphate synthase (GMPS), progesterone receptor (PR), CD40, and p21 (cyclin-dependent kinase inhibitor 1A)] to play an important role in ovarian cancer progression. Furthermore, the Cancer Genome Atlas dataset validated the differential expression of these four genes, which were associated with prognosis in ovarian cancer patients. In conclusion, this study profiled differentially expressed genes using the ovarian cancer progression model and identified four (i.e., GMPS, PR, CD40, and p21) as prognostic markers for ovarian cancer patients. Future studies of prospective patients could further verify the clinical usefulness of this four-gene signature. 
1 Prognostic values of GMPS, PR, CD40, and p21 in ovarian cancer

2

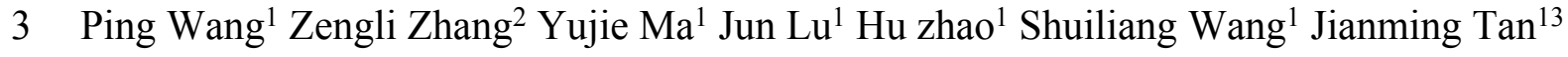

4 Bingyan $\mathrm{Li}^{2}$

5

6

$7 \quad$ 1Fujian Key Laboratory of Transplant Biology, Fuzhou General Hospital, Fuzhou, Fujian, China

8 2Department of Toxicology, School of Public Health, Soochow University, Jiangsu Suzhou,

9 China

$10{ }^{3}$ Fujian Hongyi Health Institute, Fuzhou, China

11

12 Corresponding authors: Dr. Bingyan Li, Tel.: 86-13771875966; Email: bingyanli@suda.edu.cn

13 Or Dr. Jianming Tan, Tel.: 86-13705005511; Email: tanjm156@xmu.edu.cn

14

15 Running title: Biomarker prediction of ovarian cancer prognosis 


\section{Abstract}

19 Early detection and prediction of prognosis and treatment responses are all the keys in improving 20 survival of ovarian cancer patients. This study profiled an ovarian cancer progression model to 21 identify prognostic biomarkers for ovarian cancer patients. Mouse ovarian surface epithelial cells 22 (MOSECs) can undergo spontaneous malignant transformation in vitro cell culture. These were 23 used as a model of ovarian cancer progression for alterations in gene expression and signaling 24 detected using the Illumina HiSeq2000 Next-Generation Sequencing platform and 25 bioinformatical analyses. The differential expression of four selected genes was identified using 26 the gene expression profiling interaction analysis (http://gepia.cancer-pku.cn/) and then 27 associated with survival in ovarian cancer patients using the Cancer Genome Atlas dataset and 28 the online Kaplan-Meier Plotter (www.kmplot.com) data. The data showed 263 aberrantly 29 expressed genes, including 182 up-regulated and 81 down-regulated genes between the early and 30 late stages of tumor progression in MOSECs. The bioinformatic data revealed four genes [i.e., 31 guanosine 5'-monophosphate synthase (GMPS), progesterone receptor (PR), CD40, and p21 32 (cyclin-dependent kinase inhibitor 1A)] to play an important role in ovarian cancer progression.

33 Furthermore, the Cancer Genome Atlas dataset validated the differential expression of these four

34 genes, which were associated with prognosis in ovarian cancer patients. In conclusion, this study 35 profiled differentially expressed genes using the ovarian cancer progression model and identified 36 four (i.e., GMPS, PR, CD40, and p21) as prognostic markers for ovarian cancer patients. Future 37 studies of prospective patients could further verify the clinical usefulness of this four-gene 38 signature. 
40

41

42

43

44

45

46

47

48

50

\section{Introduction}

Ovarian cancer is a lethal disease in women. Epithelial ovarian cancer accounts for approximately $90 \%$ of all ovarian malignancies (Siegel et al. 2018) and is frequently diagnosed at the advanced stages when cancer cells have already metastasized to other organs (Jayson et al. 2014). For example, ovarian cancer only represents $2.5 \%$ of all female malignancies but contributes to $5 \%$ of female cancer deaths, indicating a poor 5-year survival rate (Jayson et al. 2014). However, if diagnosed early, the 5-year survival rate could reach approximately $93 \%$ (Torre et al. 2018). Thus, early tumor detection and effective prognosis prediction are the keys in improving survival of ovarian cancer patients. To this end, previous studies have searched and evaluated biomarkers to diagnose this now deadly disease early and to predict survival or treatment responses or target the biomarker genes to develop novel therapies for ovarian cancer (Jayson et al. 2014) as well as analyzed the differential gene expression patterns between mucinous and clear cell ovarian cancers or between low-grade, low malignant potential and highgrade, metastatic ovarian cancer (Bonome et al. 2005; Meinhold-Heerlein et al. 2005). Other studies associated alterations in gene or gene expression as biomarkers for the early detection or risk assessment of ovarian cancer (Earp et al. 2018; Urban et al. 2018). However, to date, there are no useful or reliable molecular or clinical markers available for such a purpose (Force et al. 2018). The current approaches or analyses of differential gene expression profiles usually compare ovarian cancer vs. normal tissues, which leads to limited data; nevertheless, the characterization of differential gene expression profiles between early stage precursor lesions and ovarian cancer could provide novel insights into identifying biomarkers for early detection or prognosis prediction and therapeutic targets of ovarian cancer.

We established and characterized an in vitro cell model of mouse epithelial ovarian cancer progression according to the method of previous research (Gamwell et al. 2012). This cell model system uses isolated ovarian surface epithelial cells (MOSECs) from mice and cultures them in vitro. These MOSECs can undergo spontaneous malignant transformation into epithelial ovarian cancer cells (Flesken-Nikitin et al. 2013b; Gamwell et al. 2012; McCloskey et al. 2014; Roberts 
67 et al. 2005). During in vitro cell culture and passages, the MOSECs show morphology changes

68

69

70

71

72

73

74

75

76

77

78 and gene alterations (Flesken-Nikitin et al. 2013b; Gamwell et al. 2012; McCloskey et al. 2014; Roberts et al. 2005), which could be a good in vitro cell model to mimic human ovary carcinogenesis. Previous studies showed that the spontaneously transformed MOSECs had reliable formation of homologous HGSC tumors. MOSE-I cells refer as a pre-cancerous benign tumor, while MOSE-II cells are malignantly transformed cells (McCloskey et al. 2014).

To date, epithelial ovarian cancer has a terrible prognosis and detection of differentially expressed genes (DEGs) in ovarian cancer could better stratify the risk in predicting ovarian cancer in women and/or treatment responses. Thus, in this study, we first isolated MOSECs from six-month female BALB/c mice and continuously cultured and passaged them in more than 35 passages, during which we obtained early passaging MOSECs and later passaging MOSECs and named them MOSE-I and MOSE-II, respectively. These MOSE cells model is a credible in research on ovarian cancer because these two types of MOSECs displayed distinguished cell morphology and growth potential in soft agar. We thus utilized them to profile differentially expressed genes using the Illumina HiSeq2000 Next-Generation Sequencing (NGS) platform and bioinformatical analyses and to identify prognostic biomarkers for ovarian cancer patients using the gene expression profiling interaction analysis (GEPIA; http:/gepia.cancer-pku.cn/). Our hypothesis was to utilize MOSECs to identify and evaluate DEGs as biomarkers for ovarian cancer early diagnosis and prognosis prediction; thus, we then associated these DEGs with survival of ovarian cancer patients using the Cancer Genome Atlas dataset and the online Kaplan-Meier Plotter (www.kmplot.com) data. We also used the gene ontology (GO) and the Kyoto Encyclopedia of Genes (KEGG) tools to assess the functions of these DEGs for better understanding of ovarian cancer biology.

\section{Materials and Methods}

Isolation and culture of MOSE cells

3 The animal protocol for this study was approved by the Institutional Animal Care and Use 4 Committee (IACUC) of Fuzhou General Hospital (Fujian, China) and followed the regulatory 
95 animal care guidelines of the United State National Institute of Health (Bethesda, MD, USA). In

96 this study, we obtained six-month female BALB/c mice from the Shanghai SLAC Laboratory

97 Animal Co., Ltd. (Shanghai, China). We isolated mouse ovarian surface epithelial cells

98 (MOSECs) and cultured them in the "MOSE medium" containing a -Minimum Essential

99 Medium from Thermo-Fisher Scientific Company (Waltham, MA, USA) supplemented with 4\%

100 heat-inactivated 3:1 donor bovine serum: fetal bovine serum (Gibco, Gaithersburg, MD, USA), 5

$101 \mathrm{U} / \mathrm{ml}$ of penicillin and $5 \mu \mathrm{g} / \mathrm{ml}$ of streptomycin solution (Invitrogen, Carlsbad, CA), $0.1 \mu \mathrm{g} / \mathrm{ml}$

102 of gentamicin (Invitrogen) at $37^{\circ} \mathrm{C}$ with $5 \% \mathrm{CO}_{2}$ according to the previous described protocols

103 (Gamwell et al. 2012; McCloskey et al. 2014). The MOSECs with spontaneously malignant

104 transformation phenotypes were maintained in the MOSE medium according to a previous study

105 (Flesken-Nikitin et al. 2013a), which have two phases, i.e., the early stage (MOSE-I; normal

106 epithelial cells) and the later stage (MOSE-II; various phenotypes of ovarian cancer cells).

107

Generation and characterization of MOSE-I and MOSE-II cells

109 To induce spontaneous malignant transformation of MOSECs, we grew and passaged the

110 primary cultured MOSECs in the MOSE medium continuously. The early passages of MOSECs

111 were MOSE-I, whereas MOSECs at 35 passages or more become MOSE-II. To distinguish them,

112 we monitored their morphology under an inverted phase contrast microscope (Thermo-Fisher,

113 Waltham, MA, USA) and grew them in the soft agar. Specifically, cells were passaged from

114 adherent cultures using $0.05 \%$ trypsin, washed with phosphate-buffered saline (PBS) to make a

115 single cell suspension by passing cells through a syringe, and then 100 cells were plated into

116 each of the 40-mm cell culture dishes and grown for 14 days. The cells were then stained with

117 crystal violet (Sigma Aldrich Chemicals, St. Louis, MO, USA), photographed under an inverted

118 microscope, and counted. For the soft agar assay, we first made the base layer agar by mixing 1:1

119 of 2×Ham's F-12: the MOSE medium (Sigma Aldrich Chemicals, St. Louis, MO, USA) in 60-

$120 \mathrm{~mm}$ cell culture dishes and then mixing the cell suspension $\left(2.5 \times 10^{4}\right)$ with the ultrapure LMP

121 agarose (Invitrogen, Carlsbad, CA, USA) at $37^{\circ} \mathrm{C}$ and then pouring this into the top of the base

122 layer of agar and incubating them at $37^{\circ} \mathrm{C}$ for 7 days. The cell colonies were photographed using

123 the EVOS XL imaging system (Invitrogen) and quantified using Image J software (National

124 Institute of Heath, Bethesda, MD, USA).

125 
126 Next-generation sequencing of differentially expressed genes between MOSE-I and MOSE-II 127 cells

128 To profile differentially expressed genes between MOSE-I and MOSE-II cells, we performed 129 next-generation sequencing of differentially expressed genes between MOSE-I and MOSE-II 130 cells. In brief, the total cellular RNA was isolated from MOSE-I and MOSE-II cells using Trizol

131 Reagent (Invitrogen) according to the manufacturer's protocol. After RNA quantitation and 132 reverse transcription into cDNA, we prepared the cDNA library for each cell type using Illumina 133 TruSeq Libraries (Illumina, \#RS-122-2001, NY USA) and then performed next-generation 134 sequencing of differentially expressed genes between MOSE-I and MOSE-II cells using the 135 Illumina HiSeq2000 NGS platform available at Tigem Institute in Pozzuoli (Naples).

Bioinformatic analysis with the Gene Ontology (GO) terms and the Kyoto Encyclopedia of

138 Genes and Genomes (KEGG) database

139 These differentially expressed genes (DEGs) were bioinformatically analyzed using the GO term 140 to annotate the unique biological functions of these DEGs. We then further analyzed their

141 signaling in the pathways using the KEGG database. The significant GO terms and pathways 142 were generated using Fisher's exact test and statistically corrected using the false discovery rate 143 (FDR) of the $p$-values.

Construction of DEGs into a protein-protein interaction (PPI) network

146 After bioinformatic analysis of these DEGs with the GO terms and the KEGG database, we 147 further constructed these DEGs into the PPI network using STRING (version 9.1, $148 \mathrm{http} / /$ www.string-db.org/) according to the previous description (Franceschini et al. 2013). This

149 web resource contains a biological database for the comprehensive prediction of the known 150 protein-protein interactions. We uploaded our DEGs into the STRING database; the web site

151 then generated the PPIs for these DEGs. We used a combined score of $>0.5$ as the cut-off 152 criterion to identify any given protein interacts with another one and then imported these PPI 153 pairs into the Cytoscape software (http://www.cytoscape.org/) according to previous research 
154 (Saito et al. 2012) to help us to construct the PPI network, in which the hub nodes (the key 155 proteins that possess important biological functions) were revealed by calculating the degree to 156 connect to other proteins vs. non-connected ones.

157

158 Gene expression profiling interaction analysis (GEPIA)

159 GEPIA is a web tool (http://gepia.cancer-pku.cn/) to profile gene expressions between tumor and 160 non-tumor tissues and provides interactive data analyses. In this study, we utilized this online 161 tool to analyze the levels of four selected DEGs (i.e., GMPS, PR, CD40, and p21) between 162 ovarian cancer specimens and normal controls and performed a Student's t-test to for statistical 163 significance with a cut-off of $p$ value $<0.05$ and four-fold changes.

\section{The TCGA database and cBioPortal}

166 The Cancer Genome Atlas database was used to store both DEGs and clinicopathological data on 30 different human cancers (Tomczak et al. 2015). In this study, we retrieved the ovary invasive carcinoma (TCGA, Provisional) dataset, which includes DEGs data on 606 cases of ovarian cancer vs. 311 normal tissues. We then put our DEGs data vs. TCGA data into the cBioPortal (www.cbioportal.org), which is a web resource to help explore, visualize, and analyze DEGs data (Gao et al. 2013). The overall survival (OS) and disease-free survival (DFS) were stratified by these DEGs and then calculated according to the cBioPortal's online instructions. In addition, we also generated the Kaplan-Meier curves of ovarian cancer patients stratified by the expression of GMPS, PR, Cd40, and p21 mRNA levels using the online Kaplan-Meier Plotter (www.kmplot.com) according to a previous study (Gyorffy et al. 2013). This website accumulated data on the gene expression and survival of 4,142 ovary cancer patients. We analyzed the relapse-free survival (RFS) of ovarian cancer patients stratified by high vs. low expression of GMPS, PR, CD40, and p21 using the Kaplan-Meier curves and the log rank test and the hazard ratio with $95 \%$ confidence intervals (CI). The reason to select these four top hub genes was because they possessed a number-at-risk below the main plot (curve). 


\section{Results}

\section{Characterization of MOSE-I and MOSE-II cells}

184 In this study, we isolated MOSECs from female BALB/c mice and passaged them into MOSE-I and MOSE-II cells in vitro. We found that the early passages of MOSE-I cells grew slowly with doubling time of $48 \mathrm{~h}$, whereas the growth rate MOSE-I increased when it was passaged more than 35 passages. Morphologically, MOSE-I cells started to lose the epithelial "cobblestone"-like appearance under an inverted microscope, which is the characteristic of early passage MOSE-I cells (Figure 1A), consistent with previous studies (Gamwell et al. 2012; McCloskey et al. 2014). Continual passaging of MOSE-I for more than 35 passages led it to be established as MOSE-II.

191 MOSE-II loses the epithelial "cobblestone"-like morphology and transitions to a more 192 mesenchymal morphology (Figure 1A). To distinguish them, we monitored their morphology 193 under an inverted phase contrast microscope and grew them in soft agar. The latter assay measures the anchorage-independent growth, which is the characteristic of transformed cells in vitro. Our data showed that MOSE-II cells were able to form colonies in the soft agar, whereas

196 MOSE-I could not (Figure 1BD). We also assessed their proliferation capacity using the plate colony formation assay and found that MOSE-II formed more colonies with larger cell sizes than those of MOSE-I cells (Figure 1CEF).

\section{Profiling of differentially expressed genes (DEGS) between MOSE-I and MOSE-II cells}

201 Using this cell model of MOSE-I and II, we profiled DEGs using the Illumina HiSeq2000 NGS 202 platform. Our experiments were in three biological replicates to reduce sample variations due to 203 cell heterogeneous cultures. MOSE-I cells were randomly selected at Passage 5 (P5), P15, and 204 P25, respectively, while MOSE-II cells were selected at P50, P70 and P90, respectively. Among 205 them, 14218 genes were detected and analyzed. We found a total of 263 DEGs, which included 206 182 up-regulated and 81 down-regulated DEGs using Volcano plots (Figure 2). The cut-off 
207 values for the up-regulated DEGs were $\log 2 \mathrm{FC}>2$ and $p<0.05$, while the down-regulated 208 DEGs were $\log 2 \mathrm{FC}<-2, p<0.05$ (Table 1 ).

209

210 Bioinformatical data on the GO terms, KEGG, and PPI network of the DEGs

211 The GO terms showed that these DEGs formed several important terms in cell biology, such as 212 positive regulation of cell proliferation, positive regulation of transcription from RNA 213 polymerase II promoter and signal transduction (Figure 3B). The KEGG pathway analysis

214 showed that these DEGs-formed hub genes were enriched in the pathways related to the PI3K-

215 Akt signaling and pathways in cancer (Figure 3A), both of which are positively associated with 216 ovarian cancer development (Kurose et al. 2001; Li et al. 2014; Rossig et al. 2001). Furthermore, 217 the PPI network of these DEGs is shown in Figure 4. In particular, there were 35 nodes forming 218 the hub genes from 27 up-regulated and 8 down-regulated genes (Table 2).

219

220

Association of these DEGs-formed hub gene expressions with overall survival of ovarian cancer 221 patients

222 We then associated the expression of these DEGs-formed hub genes with OS and DFS of ovarian 223 cancer patients using TCGA database data. We first assessed the expression of all 35 hub genes 224 in 182 tissue samples out of 263 ovary invasive cancer patients and found that among these genes, four (GMPS, PR, CD40, and p21) had the alteration rates of more than $10 \%$ (Figure $5 \mathrm{~A}$ ).

We then plotted the Kaplan-Meier curves and performed a log-rank test to associate them with

OS and DFS of patients. Our data showed that the aberrant expression of GMPS, PR, CD40, and 228 p21 mRNA was associated with poorer OS in patients (Figure 5B) but not with DFS in patients 229 (Figure 5C).

230 Indeed, these four genes were also differentially expressed in ovarian cancer tissues vs. 231 normal tissues; specifically, GMPS was highly expressed in ovary cancer tissues (Figure 6A), 232 which was associated with RFS in patients (Figure 6E). In contrast, the expression of PR, CD40, 233 and p21 mRNA was reduced in ovarian cancer tissues (Figure 6BCD), which was associated 
234 with poor RFS (Figure 6FGH).

235

\section{Discussion}

237 In the current study, we profiled DEGs between pre-malignant MOSE-I and highly malignant 238 MOSE-II cells and found 182 up-regulated and 81 down-regulated DEGs. Our bioinformatical 239 analysis showed that these DEGs function to positively regulate cell proliferation, gene 240 transcription from RNA polymerase II promoter, and signal transduction, while KEGG pathway 241 data showed that these DEGs could be related to the PI3K-Akt signaling and pathways in cancer. 242 Furthermore, the PPI network analysis of these DEGs identified 35 hub genes (27 up-regulated 243 and 8 down-regulated genes) and that four of them were associated with poor overall survival in 244 ovarian cancer patients. In addition, these four genes were also differentially expressed in 245 ovarian cancer tissues compared with human normal tissues. Specifically, GMPS was highly 246 expressed in ovary cancer tissues, which was associated with RFS, whereas the expression of PR, 247 CD40, and p21 mRNA was reduced in ovarian cancer tissues, which was associated with poor 248 RFS. In conclusion, the data from the current study profiled and identified four DEGs, which 249 could predict overall survival and recurrence-free survival in ovarian cancer patients. Future 250 prospective study will need to validate our current data before using them clinically. Indeed, this 251 in vitro cell model of ovarian cancer progression could provide a useful tool for identifying gene 252 alterations and drug effect tests. In this system, MOSEs cultured in vitro can undergo 253 spontaneously malignant transformation into ovarian cancer (McCloskey et al. 2014). 254 Morphologically, MOSE-II cells lost their normal epithelia "cobblestone" characteristic and 255 were able to form soft agar colonies (McCloskey et al. 2014) as well as gene alterations (Lv et al. 256 2012; Roby et al. 2000; Urzua et al. 2010). When MOSE-II cells were injected into the

257 peritoneal cavity of immunodeficient animals, tumor metastases and bloody ascites formed in the 258 mouse peritoneal cavity (Roberts \& Schmelz 2013; Roby et al. 2000), which is typical of 259 advanced human ovarian cancer (Ahmed \& Stenvers 2013). In 2014, McCloskey and his 260 colleagues discovered that differentially expressed genes of MOSE-II were consistent with the 
261 differential genes of human high-grade serous ovarian cancer (HGSC) tumor samples and 262 previous studies of ovarian cancer cell lines (McCloskey et al. 2014). HGSC tumors after 263 immunohistochemical profiles confirmed that MOSE-II can be used as a homologous model of 264 HGSC. Finally, MOSE-II expressing SCA1 appeared to be more aggressive than ovarian cancer 265 cell lines, with increased colony formation efficiency in vitro and faster onset of tumors in vivo 266 (McCloskey et al. 2014). Thus, this model of cells is useful in the future study of ovarian cancer 267 prevention and treatment (Ricci et al. 2013). In the current study, we profiled DEGs between 268 MOSE-I and MOSE-II cells using this model system and found that DEGs were compatible with 269 human disease. Furthermore, our PPI network analysis identified that 35 significant nodes and 270 nine genes participate in the PI3K-Akt signaling pathway, which confirmed data from a previous 271 study, indicating potential therapeutic targets for ovarian cancer (Li et al. 2014). These genes are 272 frequently altered, such as PIK3CA mutation or amplification in up to $30 \%$ ovarian cancer 273 patients, while PTEN expression was lost in up to 40\% of patients (Campbell et al. 2004; Kurose 274 et al. 2001). In addition, six of these 35 hub genes are a part of the Rap1 signal pathway, and a 275 previous study reported them to be associated with serous ovarian cancer metastasis (Che et al. 276 2015).

277 Furthermore, these DEGs were annotated into the GO terms and were shown to positively 278 regulate cell proliferation, which is one of six essential cancer hallmarks: self-sufficiency in 279 growth signals (Hanahan \& Weinberg 2000). Indeed, the positive regulation of cell proliferation 280 is the basis of cancer development and progression. Moreover, each of these pathways identified 281 in the current study can promote or transform normal cells into cancer cells (Evan \& Vousden 282 2001). Furthermore, our current study identified a four-gene signature to predict overall survival 283 of ovarian cancer patients. Specifically, GMPS, a guanosine 5'-monophosphate synthase, is an 284 enzyme that converts xanthosine monophosphate to guanosine monophosphate. Thus, GMPS is 285 important in nucleotide biosynthesis for normal cell proliferation and oncogenesis. Reddy's data 286 showed that GMPS in combination of TRIM21 with USP7 formed a molecular cascade that 287 controls p53 stability in response to DNA damage or nucleotide deprivation. Therefore, GMPS is 
288 a classical biosynthetic enzyme that promotes cell growth and DNA replication, and is also a key 289 center for p53-restricted cell proliferation (Reddy et al. 2014). In our current study, we found that

290 GMPS was highly expressed in ovary cancer tissues compared with that of non-tumor tissues and 291 that GMPS expression was associated with RFS of patients. This piece of data is novel and has

292 been not reported in literature before. A previous study showed that GMPS was an important p53 293 repression target in liver cancer cells (Holzer et al. 2017), which further indicates the importance 294 of GMPS in oncogenesis. As we know, p53 is a tumor suppressor protein and can prevent 295 aberrant cell proliferation, which may be through the repression of GMPS activity (Holzer et al. 296 2017). In addition, $P R$, as the nuclear receptor, functions to regulate the development and cycle 297 of hormone-responsive tissues, such as the mammary glands and reproductive tract. Several 298 previous studies demonstrated PR expression as a biomarker to predict better prognosis of 299 endometrioid and high-grade serous ovarian carcinoma (Jonsson et al. 2015; Lee et al. 2005; 300 Lenhard et al. 2012; Sieh et al. 2013), while lost PR expression was associated with advanced 301 stages of ovarian cancer (Feng et al. 2016). Indeed, progesterone and progestin were shown to 302 play a protective role against ovarian carcinogenesis (Edmondson \& Monaghan 2001), and PR 303 expression was a favorable prognostic marker associated with longer progression-free survival in 304 ovarian cancer patients (Tangjitgamol et al. 2009; van Kruchten et al. 2015; Wong et al. 2007). 305 Our current data confirm these previous data. Furthermore, CD40 is a transmembrane 306 glycoprotein and the member of the tumor necrosis factor receptor superfamily, which can 307 mediate a broad variety of immune and inflammatory responses (Grewal \& Flavell 1998). CD40 308 is frequently expressed in different immune cells and endothelial and epithelial cells. The 309 binding of CD40 to CD40 ligand was shown to have various physiological and pathological roles

310 in the human body (Grewal \& Flavell 1998; van Kooten \& Banchereau 2000). A previous study

311 demonstrated that CD40 ligands enhanced the sensitivity of epithelial ovarian cancer cells to 312 cisplatin treatment (Qin et al. 2016). CD40 was highly expressed in ovarian cancer cell lines and 313 tumor samples but not in normal ovarian tissue (Zhou et al. 2012). In our current study, we found 314 elevated CD40 expression in MOSE-II cells compared with MOSE-I cells; however, CD40 
315 expression was reduced in ovarian cancer tissues, which is opposite the findings of a previous 316 study (Zhou et al. 2012). Thus, further study is needed to determine the reason for this 317 discrepancy. In addition, p21 also called as CDKN1A cyclin-dependent kinase inhibitor 1A, 318 functions to regulate cell growth arrest by inhibiting Cdks, which is required for cell cycle 319 transition from the G1 to $\mathrm{S}$ phase (Xiong et al. 1993). Through the interaction with the 320 proliferating cell nuclear antigen (PCNA),/p21 was able to inhibit DNA replication (Rossig et al.

321 2001). Our current study showed that p21 was highly expressed in normal tissues but reduced in 322 ovarian cancer tissues, which was associated with better survival of patients, consistent with a 323 previous study (Alves et al. 2018). Indeed, a previous study demonstrated that pyridine 324 derivative-induced ovarian cancer cell senescence occurred through p21 activation (Shang et al. 325 2018). However, other studies reported that CDKN1A/p21 expression promoted breast cancer 326 and mediated drug resistance (Cheng et al. 2010; Hawthorne et al. 2009), and clinical studies

327 have indicated that high p21 expression was correlated with poor prognosis of gastric and 328 esophageal cancers (Liu et al. 2014; Taghavi et al. 2010). Thus, further study is needed to clarify 329 this discrepancy.

330 However, our current study does have some limitations; for example, our current study just 331 profiled differentially expressed genes in ovarian cancer and associated them with prognosis of 332 ovarian cancer as well as performed bioinformatical analysis to associate four of them with 333 ovarian cancer progression; however, much more are needed in precise research on their

334 biological functions and role in ovarian cancer development and progression. Furthermore, 335 future validation of these DEGs in ovarian cancer is also needed before any applications to 336 patients.

338 Conclusions

339 Our current study revealed a four-gene signature after profiling a cell model of ovarian cancer 340 progression to predict overall survival and recurrence-free survival in ovarian cancer patients.

341 Future study will verify these data using prospective ovarian cancer patients. 


\section{References}

344

345

346

347

348

349

350

351

352

353

354

355

356

357

358

359

360

361

362

363

364

365

366

367

368

369

370

371

372

373

374

375

376

377

378

379

380

381

382

Ahmed N, and Stenvers KL. 2013. Getting to know ovarian cancer ascites: opportunities for targeted therapybased translational research. Front Oncol 3(256 DOI:10.3389/fonc.2013.00256.

Alves MR, NC EM, Barros-Filho MC, do Amaral NS, Silva FIB, Baiocchi Neto G, Soares FA, de Brot Andrade L, and Rocha RM. 2018. Downregulation of AGR2, p21, and cyclin D and alterations in p53 function were associated with tumor progression and chemotherapy resistance in epithelial ovarian carcinoma. Cancer Med DOI:10.1002/cam4.1530.

Bonome T, Lee JY, Park DC, Radonovich M, Pise-Masison C, Brady J, Gardner GJ, Hao K, Wong WH, Barrett JC, Lu KH, Sood AK, Gershenson DM, Mok SC, and Birrer MJ. 2005. Expression profiling of serous low malignant potential, low-grade, and high-grade tumors of the ovary. Cancer Res 65(22):1060210612 DOI:10.1158/0008-5472.CAN-05-2240.

Campbell IG, Russell SE, Choong DY, Montgomery KG, Ciavarella ML, Hooi CS, Cristiano BE, Pearson RB, and Phillips WA. 2004. Mutation of the PIK3CA gene in ovarian and breast cancer. Cancer Res 64(21):76787681 DOI:10.1158/0008-5472.CAN-04-2933.

Che YL, Luo SJ, Li G, Cheng M, Gao YM, Li XM, Dai JM, He H, Wang J, Peng HJ, Zhang Y, Li WY, Wang H, Liu B, and Linghu H. 2015. The C3G/Rap1 pathway promotes secretion of MMP-2 and MMP-9 and is involved in serous ovarian cancer metastasis. Cancer Lett 359(2):241-249 DOI:10.1016/j.canlet.2015.01.019.

Cheng X, Xia W, Yang JY, Hsu JL, Chou CK, Sun HL, Wyszomierski SL, Mills GB, Muller WJ, Yu D, and Hung MC. 2010. Activation of $\mathrm{p} 21(\mathrm{CIP} 1 / \mathrm{WAF} 1)$ in mammary epithelium accelerates mammary tumorigenesis and promotes lung metastasis. Biochem Biophys Res Commun 403(1):103-107 DOI:10.1016/j.bbrc.2010.10.126.

Earp M, Tyrer JP, Winham SJ, Lin HY, Chornokur G, Dennis J, Aben KKH, Anton-Culver H, Antonenkova N, Bandera EV, Bean YT, Beckmann MW, Bjorge L, Bogdanova N, Brinton LA, Brooks-Wilson A, Bruinsma F, Bunker CH, Butzow R, Campbell IG, Carty K, Chang-Claude J, Cook LS, Cramer DW, Cunningham JM, Cybulski C, Dansonka-Mieszkowska A, Despierre E, Doherty JA, Dork T, du Bois A, Durst M, Easton DF, Eccles DM, Edwards RP, Ekici AB, Fasching PA, Fridley BL, Gentry-Maharaj A, Giles GG, Glasspool R, Goodman MT, Gronwald J, Harter P, Hein A, Heitz F, Hildebrandt MAT, Hillemanns P, Hogdall CK, Hogdall E, Hosono S, Iversen ES, Jakubowska A, Jensen A, Ji BT, Jung AY, Karlan BY, Kellar M, Kiemeney LA, Kiong Lim B, Kjaer SK, Krakstad C, Kupryjanczyk J, Lambrechts D, Lambrechts S, Le ND, Lele S, Lester J, Levine DA, Li Z, Liang D, Lissowska J, Lu K, Lubinski J, Lundvall L, Massuger L, Matsuo K, McGuire V, McLaughlin JR, McNeish I, Menon U, Milne RL, Modugno F, Moysich KB, Ness RB, Nevanlinna H, Odunsi K, Olson SH, Orlow I, Orsulic S, Paul J, Pejovic T, Pelttari LM, Permuth JB, Pike MC, Poole EM, Rosen B, Rossing MA, Rothstein JH, Runnebaum IB, Rzepecka IK, Schernhammer E, Schwaab I, Shu XO, Shvetsov YB, Siddiqui N, Sieh W, Song H, Southey MC, Spiewankiewicz B, Sucheston-Campbell L, Tangen IL, Teo SH, Terry KL, Thompson PJ, Thomsen L, Tworoger SS, van Altena AM, Vergote I, Vestrheim Thomsen LC, Vierkant RA, Walsh CS, Wang-Gohrke S, Wentzensen N, Whittemore AS, Wicklund KG, Wilkens LR, Woo YL, Wu AH, Wu X, Xiang YB, Yang H, Zheng W, Ziogas A, Lee AW, Pearce CL, Berchuck A, Schildkraut JM, Ramus SJ, Monteiro ANA, Narod SA, Sellers TA, Gayther SA, Kelemen LE, Chenevix-Trench G, Risch HA, Pharoah PDP, Goode EL, and Phelan CM. 2018. Variants in genes encoding small GTPases and 
383

384

385

386

387

388

389

390

391

392

393

394

395

396

397

398

399

400

401

402

403

404

405

406

407

408

409

410

411

412

413

414

415

416

417

418

419

420

421

422

423

association with epithelial ovarian cancer susceptibility. PLoS One 13(7):e0197561 DOI:10.1371/journal.pone.0197561.

Edmondson RJ, and Monaghan JM. 2001. The epidemiology of ovarian cancer. Int J Gynecol Cancer 11(6):423429

Evan GI, and Vousden KH. 2001. Proliferation, cell cycle and apoptosis in cancer. Nature 411(6835):342-348 DOI: $10.1038 / 35077213$.

Feng Z, Wen H, Bi R, Ju X, Chen X, Yang W, and Wu X. 2016. A clinically applicable molecular classification for high-grade serous ovarian cancer based on hormone receptor expression. Sci Rep $\mathbf{6}(25408$ DOI:10.1038/srep25408.

Flesken-Nikitin A, Hwang C-I, Cheng C-Y, Michurina TV, Enikolopov G, and Nikitin AY. 2013a. Ovarian surface epithelium at the junction area contains a cancer-prone stem cell niche. Nature 495(7440):241-245

Flesken-Nikitin A, Hwang CI, Cheng CY, Michurina TV, Enikolopov G, and Nikitin AY. 2013b. Ovarian surface epithelium at the junction area contains a cancer-prone stem cell niche. Nature 495(7440):241-245 DOI:10.1038/nature11979.

Force USPST, Grossman DC, Curry SJ, Owens DK, Barry MJ, Davidson KW, Doubeni CA, Epling JW, Jr., Kemper AR, Krist AH, Kurth AE, Landefeld CS, Mangione CM, Phipps MG, Silverstein M, Simon MA, and Tseng CW. 2018. Screening for Ovarian Cancer: US Preventive Services Task Force Recommendation Statement. Jama 319(6):588-594 DOI:10.1001/jama.2017.21926.

Franceschini A, Szklarczyk D, Frankild S, Kuhn M, Simonovic M, Roth A, Lin J, Minguez P, Bork P, von Mering C, and Jensen LJ. 2013. STRING v9.1: protein-protein interaction networks, with increased coverage and integration. Nucleic Acids Res 41(Database issue):D808-815 DOI:10.1093/nar/gks1094.

Gamwell LF, Collins O, and Vanderhyden BC. 2012. The mouse ovarian surface epithelium contains a population of LY6A (SCA-1) expressing progenitor cells that are regulated by ovulation-associated factors. Biol Reprod 87(4):80 DOI:10.1095/biolreprod.112.100347.

Gao J, Aksoy BA, Dogrusoz U, Dresdner G, Gross B, Sumer SO, Sun Y, Jacobsen A, Sinha R, Larsson E, Cerami E, Sander C, and Schultz N. 2013. Integrative analysis of complex cancer genomics and clinical profiles using the cBioPortal. Sci Signal 6(269):pl1 DOI:10.1126/scisignal.2004088.

Grewal IS, and Flavell RA. 1998. CD40 and CD154 in cell-mediated immunity. Annu Rev Immunol 16(111-135 DOI:10.1146/annurev.immunol.16.1.111.

Gyorffy B, Surowiak P, Budczies J, and Lanczky A. 2013. Online survival analysis software to assess the prognostic value of biomarkers using transcriptomic data in non-small-cell lung cancer. PLoS One 8(12):e82241 DOI:10.1371/journal.pone.0082241.

Hanahan D, and Weinberg RA. 2000. The hallmarks of cancer. Cell 100(1):57-70

Hawthorne VS, Huang WC, Neal CL, Tseng LM, Hung MC, and Yu D. 2009. ErbB2-mediated Src and signal transducer and activator of transcription 3 activation leads to transcriptional up-regulation of p21Cip1 and chemoresistance in breast cancer cells. Mol Cancer Res 7(4):592-600 DOI:10.1158/1541-7786.MCR-08-0316.

Holzer K, Drucker E, Roessler S, Dauch D, Heinzmann F, Waldburger N, Eiteneuer EM, Herpel E, Breuhahn K, Zender L, Schirmacher P, Ori A, and Singer S. 2017. Proteomic Analysis Reveals GMP Synthetase as p53 Repression Target in Liver Cancer. Am J Pathol 187(2):228-235 DOI:10.1016/j.ajpath.2016.09.022.

Jayson GC, Kohn EC, Kitchener HC, and Ledermann JA. 2014. Ovarian cancer. Lancet 384(9951):1376-1388 
424

425

426

427

428

429

430

431

432

433

434

435

436

437

438

439

440

441

442

443

444

445

446

447

448

449

450

451

452

453

454

455

456

457

458

459

460

461

462

463

464

DOI:10.1016/S0140-6736(13)62146-7.

Jonsson JM, Skovbjerg Arildsen N, Malander S, Masback A, Hartman L, Nilbert M, and Hedenfalk I. 2015. Sex Steroid Hormone Receptor Expression Affects Ovarian Cancer Survival. Transl Oncol 8(5):424-433 DOI:10.1016/j.tranon.2015.09.002.

Kurose K, Zhou XP, Araki T, Cannistra SA, Maher ER, and Eng C. 2001. Frequent loss of PTEN expression is linked to elevated phosphorylated Akt levels, but not associated with p27 and cyclin D1 expression, in primary epithelial ovarian carcinomas. Am J Pathol 158(6):2097-2106 DOI:10.1016/S0002-9440(10)64681-0.

Lee P, Rosen DG, Zhu C, Silva EG, and Liu J. 2005. Expression of progesterone receptor is a favorable prognostic marker in ovarian cancer. Gynecol Oncol 96(3):671-677 DOI:10.1016/j.ygyno.2004.11.010.

Lenhard M, Tereza L, Heublein S, Ditsch N, Himsl I, Mayr D, Friese K, and Jeschke U. 2012. Steroid hormone receptor expression in ovarian cancer: progesterone receptor $\mathrm{B}$ as prognostic marker for patient survival. $B M C$ cancer 12(553 DOI:10.1186/1471-2407-12-553.

Li H, Zeng J, and Shen K. 2014. PI $3 \mathrm{~K} / \mathrm{AKT} / \mathrm{mTOR}$ signaling pathway as a therapeutic target for ovarian cancer. Arch Gynecol Obstet 290(6):1067-1078 DOI:10.1007/s00404-014-3377-3.

Liu X, Yu H, Cai H, and Wang Y. 2014. Expression of CD24, p21, p53, and c-myc in alpha-fetoprotein-producing gastric cancer: Correlation with clinicopathologic characteristics and survival. J Surg Oncol 109(8):859-864 DOI:10.1002/jso.23599.

Lv L, Zhang T, Yi Q, Huang Y, Wang Z, Hou H, Zhang H, Zheng W, Hao Q, Guo Z, Cooke HJ, and Shi Q. 2012. Tetraploid cells from cytokinesis failure induce aneuploidy and spontaneous transformation of mouse ovarian surface epithelial cells. Cell Cycle 11(15):2864-2875 DOI:10.4161/cc.21196.

McCloskey CW, Goldberg RL, Carter LE, Gamwell LF, Al-Hujaily EM, Collins O, Macdonald EA, Garson K, Daneshmand M, Carmona E, and Vanderhyden BC. 2014. A new spontaneously transformed syngeneic model of high-grade serous ovarian cancer with a tumor-initiating cell population. Front Oncol 4(53 DOI:10.3389/fonc.2014.00053.

Meinhold-Heerlein I, Bauerschlag D, Hilpert F, Dimitrov P, Sapinoso LM, Orlowska-Volk M, Bauknecht T, Park TW, Jonat W, Jacobsen A, Sehouli J, Luttges J, Krajewski M, Krajewski S, Reed JC, Arnold N, and Hampton GM. 2005. Molecular and prognostic distinction between serous ovarian carcinomas of varying grade and malignant potential. Oncogene 24(6):1053-1065 DOI:10.1038/sj.onc.1208298.

Qin L, Qiu H, Zhang M, Zhang F, Yang H, Yang L, Jia L, Qin K, Jia L, Dou X, Cheng L, Sang M, Zhang C, Shan B, and Zhang Z. 2016. Soluble CD40 ligands sensitize the epithelial ovarian cancer cells to cisplatin treatment. Biomed Pharmacother 79(166-175 DOI:10.1016/j.biopha.2016.01.006.

Reddy BA, van der Knaap JA, Bot AG, Mohd-Sarip A, Dekkers DH, Timmermans MA, Martens JW, Demmers JA, and Verrijzer CP. 2014. Nucleotide biosynthetic enzyme GMP synthase is a TRIM21controlled relay of p53 stabilization. Mol Cell 53(3):458-470 DOI:10.1016/j.molcel.2013.12.017.

Ricci F, Broggini M, and Damia G. 2013. Revisiting ovarian cancer preclinical models: implications for a better management of the disease. Cancer Treat Rev 39(6):561-568 DOI:10.1016/j.ctrv.2013.01.005.

Roberts PC, Mottillo EP, Baxa AC, Heng HH, Doyon-Reale N, Gregoire L, Lancaster WD, Rabah R, and Schmelz EM. 2005. Sequential molecular and cellular events during neoplastic progression: a mouse syngeneic ovarian cancer model. Neoplasia 7(10):944-956

Roberts PC, and Schmelz EM. 2013. In vitro model of spontaneous mouse OSE transformation. Methods Mol Biol 1049(393-408 DOI:10.1007/978-1-62703-547-7_30. 
Roby KF, Taylor CC, Sweetwood JP, Cheng Y, Pace JL, Tawfik O, Persons DL, Smith PG, and Terranova PF. 2000. Development of a syngeneic mouse model for events related to ovarian cancer. Carcinogenesis 21(4):585-591

Rossig L, Jadidi AS, Urbich C, Badorff C, Zeiher AM, and Dimmeler S. 2001. Akt-dependent phosphorylation of p21(Cip1) regulates PCNA binding and proliferation of endothelial cells. Mol Cell Biol 21(16):5644-5657 DOI:10.1128/MCB.21.16.5644-5657.2001.

Saito R, Smoot ME, Ono K, Ruscheinski J, Wang PL, Lotia S, Pico AR, Bader GD, and Ideker T. 2012. A travel guide to Cytoscape plugins. Nat Methods 9(11):1069-1076 DOI:10.1038/nmeth.2212.

Shang D, Wu Y, Ding Y, Lu Z, Shen Y, Zhu F, Liu H, Zhu C, and Tu Z. 2018. Identification of a pyridine derivative inducing senescence in ovarian cancer cell lines via P21 activation. Clin Exp Pharmacol Physiol 45(5):452-460 DOI:10.1111/1440-1681.12891.

Siegel RL, Miller KD, and Jemal A. 2018. Cancer statistics, 2018. CA Cancer J Clin 68(1):7-30 DOI:10.3322/caac.21442.

Sieh W, Kobel M, Longacre TA, Bowtell DD, deFazio A, Goodman MT, Hogdall E, Deen S, Wentzensen N, Moysich KB, Brenton JD, Clarke BA, Menon U, Gilks CB, Kim A, Madore J, Fereday S, George J, Galletta L, Lurie G, Wilkens LR, Carney ME, Thompson PJ, Matsuno RK, Kjaer SK, Jensen A, Hogdall C, Kalli KR, Fridley BL, Keeney GL, Vierkant RA, Cunningham JM, Brinton LA, Yang HP, Sherman ME, Garcia-Closas M, Lissowska J, Odunsi K, Morrison C, Lele S, Bshara W, Sucheston L, JimenezLinan M, Driver K, Alsop J, Mack M, McGuire V, Rothstein JH, Rosen BP, Bernardini MQ, Mackay H, Oza A, Wozniak EL, Benjamin E, Gentry-Maharaj A, Gayther SA, Tinker AV, Prentice LM, Chow C, Anglesio MS, Johnatty SE, Chenevix-Trench G, Whittemore AS, Pharoah PD, Goode EL, Huntsman DG, and Ramus SJ. 2013. Hormone-receptor expression and ovarian cancer survival: an Ovarian Tumor Tissue Analysis consortium study. Lancet Oncol 14(9):853-862 DOI:10.1016/S1470-2045(13)70253-5.

Taghavi N, Biramijamal F, Sotoudeh M, Moaven O, Khademi H, Abbaszadegan MR, and Malekzadeh R. 2010. Association of $\mathrm{p} 53 / \mathrm{p} 21$ expression with cigarette smoking and prognosis in esophageal squamous cell carcinoma patients. World J Gastroenterol 16(39):4958-4967

Tangjitgamol S, Manusirivithaya S, Khunnarong J, Jesadapatarakul S, and Tanwanich S. 2009. Expressions of estrogen and progesterone receptors in epithelial ovarian cancer: a clinicopathologic study. Int $J$ Gynecol Cancer 19(4):620-627 DOI:10.1111/IGC.0b013e3181a44b62.

Tomczak K, Czerwinska P, and Wiznerowicz M. 2015. The Cancer Genome Atlas (TCGA): an immeasurable source of knowledge. Contemp Oncol (Pozn) 19(1A):A68-77 DOI:10.5114/wo.2014.47136.

Torre LA, Trabert B, DeSantis CE, Miller KD, Samimi G, Runowicz CD, Gaudet MM, Jemal A, and Siegel RL. 2018. Ovarian cancer statistics, 2018. CA Cancer J Clin DOI:10.3322/caac.21456.

Urban RR, Pappas TC, Bullock RG, Munroe DG, Bonato V, Agnew K, and Goff BA. 2018. Combined symptom index and second-generation multivariate biomarker test for prediction of ovarian cancer in patients with an adnexal mass. Gynecol Oncol 150(2):318-323 DOI:10.1016/j.ygyno.2018.06.004.

Urzua U, Best L, and Munroe DJ. 2010. Microarray proteomic analysis discriminates tumorigenic mouse ovarian surface epithelial cells of divergent aggressive potential. Mol Biosyst 6(12):2521-2528 DOI:10.1039/c005220e. van Kooten C, and Banchereau J. 2000. CD40-CD40 ligand. J Leukoc Biol 67(1):2-17

van Kruchten M, van der Marel P, de Munck L, Hollema H, Arts H, Timmer-Bosscha H, de Vries E, Hospers G, and Reyners A. 2015. Hormone receptors as a marker of poor survival in epithelial ovarian cancer. Gynecol 
506 Oncol 138(3):634-639 DOI:10.1016/j.ygyno.2015.06.032.

507 Wong KK, Lu KH, Malpica A, Bodurka DC, Shvartsman HS, Schmandt RE, Thornton AD, Deavers MT, 508 Silva EG, and Gershenson DM. 2007. Significantly greater expression of ER, PR, and ECAD in advanced509 stage low-grade ovarian serous carcinoma as revealed by immunohistochemical analysis. Int J Gynecol Pathol 510 26(4):404-409 DOI:10.1097/pgp.0b013e31803025cd.

511 Xiong Y, Hannon GJ, Zhang H, Casso D, Kobayashi R, and Beach D. 1993. p21 is a universal inhibitor of cyclin 512 kinases. Nature 366(6456):701-704 DOI:10.1038/366701a0.

513 Zhou Y, He J, Gou LT, Mu B, Liao WC, Ma C, Tang P, Zhou SJ, Zhou YJ, and Yang JL. 2012. Expression of 514 CD40 and growth-inhibitory activity of CD40 agonist in ovarian carcinoma cells. Cancer Immunol Immunother 515 61(10):1735-1743 DOI:10.1007/s00262-011-1194-0.

516

517 


\section{Figure 1}

Characterization of MOSE-I and MOSE-II cells in vitro.

A, Bright-field inverted microscopy. Cells were grown at Passage 20 for MOSE-I and Passage 90 for MOSE-II and then photographed at a magnification of 100x. B, The soft agar colony formation assay. MOSE-I (passage 20) and MOSE-II (passage 90) were grown in the soft agar for 7 days and photographed (magnification, 100X). C, The plate colony formation assay. MOSE-I (passage 20) and MOSE-II (passage 90) were grown for 14 days and stained with crystal violet solution and photographed (magnification, 100x). The graphs were quantified data of the colony formation assay. ${ }^{* *} p<0.01$ and ${ }^{* * *} p<0.0001$ analyzed by Student's $t$ test. The data on $E$ and $D$ were generated by the Image J software, while the data on $F$ were from the EVOS XL imaging system. 

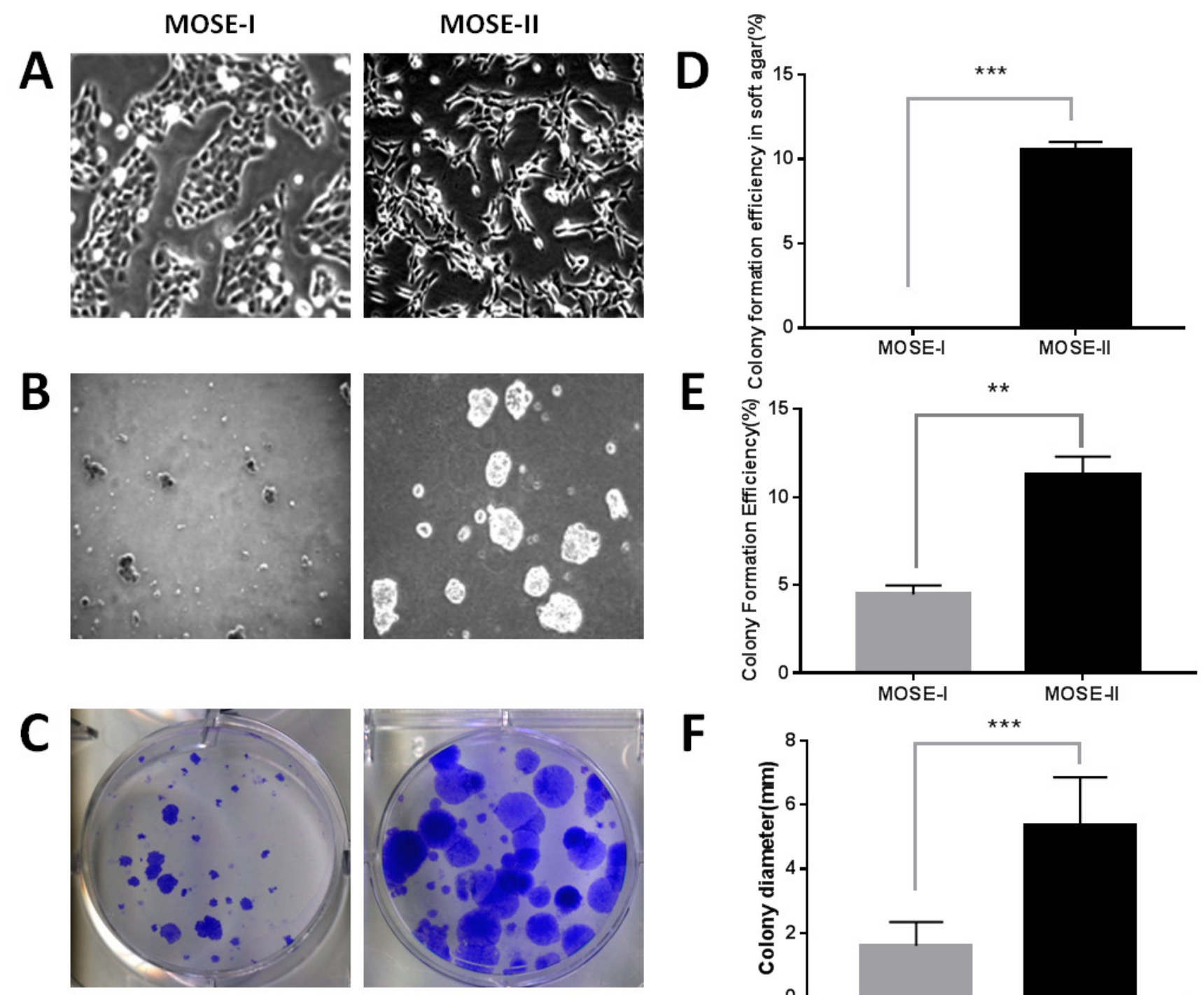

$\mathbf{F}$

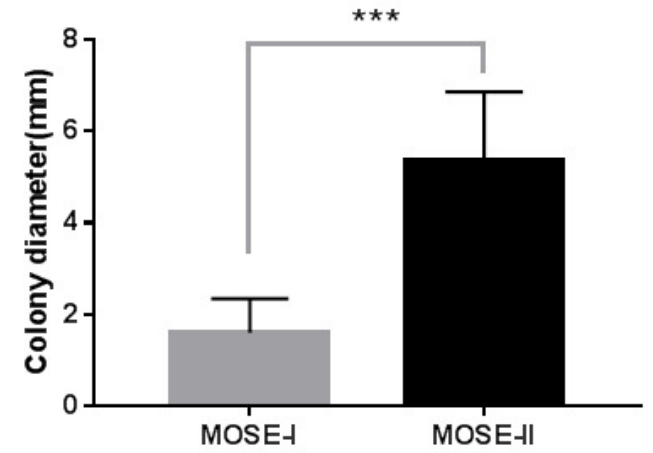




\section{Figure 2}

Identification of DEGs using Volcano plots.

The $\mathrm{X}$-axis indicates the fold change (logs value), whereas the $\mathrm{Y}$-axis shows the $p$ values (logs value). Each symbol represents a different gene, and the red/green color shows the upor downregulated genes falling under different criteria ( $p$ value and fold change threshold). A $p$ value $<0.05$ is considered as statistically significant, whereas the four fold changes were set as the threshold. 


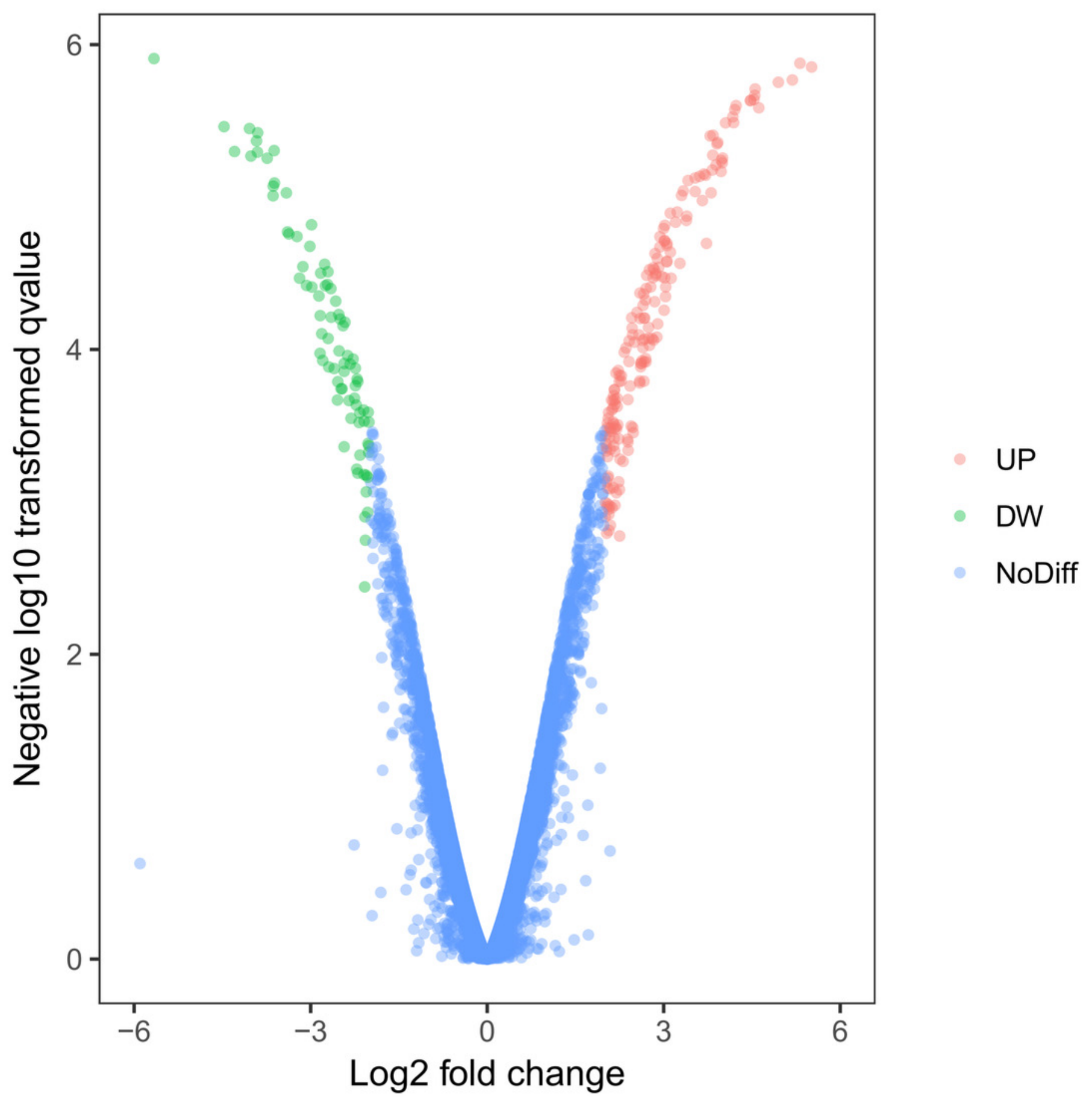


Table $\mathbf{1}$ (on next page)

DEGs between MOSE-I and MOSE-II cells. 


\begin{tabular}{|c|c|c|}
\hline Gene name & Log2 fold & P values \\
\hline \multicolumn{3}{|c|}{ Up-regulated genes } \\
\hline Ccbe1 & 5.514199 & $1.4 \mathrm{E}-06$ \\
\hline Sfrp2 & 5.316823 & $1.32 \mathrm{E}-06$ \\
\hline Cntnap2 & 5.187267 & $1.7 \mathrm{E}-06$ \\
\hline Cd55 & 4.949248 & $1.76 \mathrm{E}-06$ \\
\hline 9930013L23Rik & 4.617182 & $2.6 \mathrm{E}-06$ \\
\hline Ephx1 & 4.554543 & $1.95 \mathrm{E}-06$ \\
\hline Gnai1 & 4.548394 & $2.15 \mathrm{E}-06$ \\
\hline Ctla2a & 4.534042 & $2.29 \mathrm{E}-06$ \\
\hline Csgalnact1 & 4.478922 & $2.32 \mathrm{E}-06$ \\
\hline Ahsp & 4.473507 & $2.34 \mathrm{E}-06$ \\
\hline Pkhd111 & 4.230823 & $2.51 \mathrm{E}-06$ \\
\hline Thy1 & 4.208894 & $2.67 \mathrm{E}-06$ \\
\hline Apoe & 4.188801 & $3.25 \mathrm{E}-06$ \\
\hline Tmem $45 \mathrm{a}$ & 4.175247 & $2.98 \mathrm{E}-06$ \\
\hline Scg5 & 4.052742 & $3.26 \mathrm{E}-06$ \\
\hline Slc47a1 & 4.001494 & $5.55 \mathrm{E}-06$ \\
\hline Akr1c13 & 3.99621 & $5.96 \mathrm{E}-06$ \\
\hline $\mathrm{Nxnl} 2$ & 3.980449 & $5.75 \mathrm{E}-06$ \\
\hline Zfp385b & 3.975438 & $6.79 \mathrm{E}-06$ \\
\hline D630010B17Rik & 3.920202 & $4.38 \mathrm{E}-06$ \\
\hline \multicolumn{3}{|c|}{ Down-regulated genes } \\
\hline Cst12 & -5.66249 & $1.23 \mathrm{E}-06$ \\
\hline Pcolce2 & -4.47177 & $3.45 \mathrm{E}-06$ \\
\hline Serpina3g & -4.29413 & $5.03 \mathrm{E}-06$ \\
\hline Aif11 & -4.03994 & $3.55 \mathrm{E}-06$ \\
\hline Tmem79 & -4.01531 & $5.38 \mathrm{E}-06$ \\
\hline Emb & -3.91989 & $4.28 \mathrm{E}-06$ \\
\hline 1810065E05Rik & -3.90506 & $5.07 \mathrm{E}-06$ \\
\hline Kenk1 & -3.90055 & $3.78 \mathrm{E}-06$ \\
\hline D0H4S114 & -3.73926 & $5.56 \mathrm{E}-06$ \\
\hline Pip5k1b & -3.01345 & 2.1E-05 \\
\hline Ano1 & -3.07047 & $3.8 \mathrm{E}-05$ \\
\hline Coro $2 b$ & -3.13207 & $2.86 \mathrm{E}-05$ \\
\hline $\mathrm{Cbfa} 2 \mathrm{t} 3$ & -3.18901 & $3.41 \mathrm{E}-05$ \\
\hline Glipr1 & -3.23211 & $1.82 \mathrm{E}-05$ \\
\hline $\mathrm{Ms} 4 \mathrm{a} 3$ & -3.63888 & $9.81 \mathrm{E}-06$ \\
\hline Slain1 & -3.63583 & $8.48 \mathrm{E}-06$ \\
\hline Gmps & -3.62074 & $4.96 \mathrm{E}-06$ \\
\hline Foxc2 & -3.61526 & $8.09 \mathrm{E}-06$ \\
\hline Emp1 & -3.41282 & $9.39 \mathrm{E}-06$ \\
\hline Nkx2-3 & -3.39217 & $1.69 \mathrm{E}-05$ \\
\hline
\end{tabular}

1 
Table 2 (on next page)

The hub genes with the node degree $>5$. 


\begin{tabular}{|c|c|c|c|}
\hline number & rGene name & \begin{tabular}{|l|} 
Node \\
Degree
\end{tabular} & Regulation \\
\hline 1 & Egfr & 26 & up \\
\hline 2 & Acta2 & 23 & down \\
\hline 3 & Stat3 & 20 & up \\
\hline 4 & $\mathrm{Cd} 40$ & 12 & up \\
\hline 5 & $\mathrm{Cd} 34$ & 11 & up \\
\hline 6 & PR & 11 & up \\
\hline 7 & Isg15 & 11 & up \\
\hline 8 & Serpinb1a & 10 & up \\
\hline 9 & Rhobtb1 & 10 & up \\
\hline 10 & Gmps & 9 & down \\
\hline 11 & Gnail & 9 & up \\
\hline 12 & $\mathrm{Cd} 24 \mathrm{a}$ & 8 & down \\
\hline 13 & Ptk2b & 8 & up \\
\hline 14 & Irf7 & 8 & up \\
\hline 15 & Igf2 & 8 & up \\
\hline 16 & P21 & 8 & up \\
\hline 17 & Usp18 & 8 & up \\
\hline 18 & Apoe & 7 & up \\
\hline 19 & Gnaz & 7 & up \\
\hline 20 & Col3al & 7 & up \\
\hline 21 & Pdgfb & 7 & down \\
\hline 22 & Socs 2 & 7 & up \\
\hline 23 & Thbs1 & 6 & up \\
\hline 24 & Rhbdl3 & 6 & down \\
\hline 25 & Thy1 & 6 & up \\
\hline 26 & $\operatorname{Irgm} 2$ & 6 & up \\
\hline 27 & Gbp2 & 6 & up \\
\hline 28 & Figf & 6 & up \\
\hline 29 & Fgf10 & 6 & down \\
\hline 30 & Rasl11a & 5 & up \\
\hline 31 & Rasd2 & 5 & up \\
\hline 32 & Il4ra & 5 & up \\
\hline 33 & Serpinb9b & 5 & down \\
\hline 34 & Cend1 & 5 & down \\
\hline 35 & Fgfr2 & 5 & up \\
\hline
\end{tabular}


Figure 3

Functional and pathway enrichment analyses of DEGs-formed hub genes.

A, The Kyoto Encyclopedia of Genes and Genomes (KEGG) pathways enriched gene pathways of the DEGs-formed hub genes. B, The Gene Ontology (GO) terms of DEGS related to the biological process. C, The GO terms of DEGS related to the cellular component. D, The GO terms of DEGS related to the molecular functions.
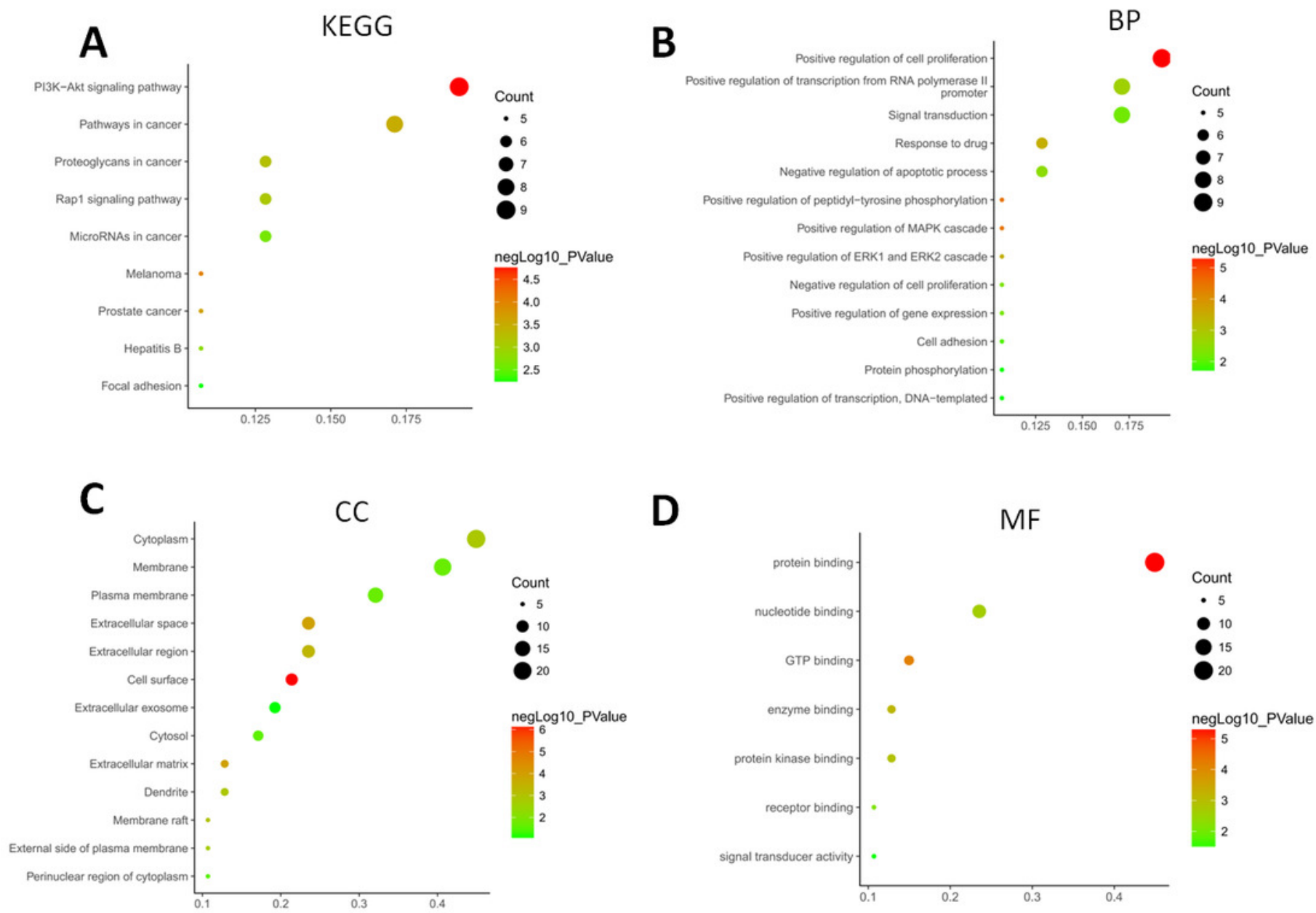


\section{Figure 4}

The DEGs-formed protein-protein interaction network.

The red and green circles represent up- and down-regulated genes, respectively. The node represents genes and edges for their role in connection between proteins. The nodes are colored based on in-between significance, and the higher the value, the darker the color, whereas the node size is proportional to the degree value, i.e., the higher the value, the bigger the size. The thicker line, the tighter the connection between the two proteins.

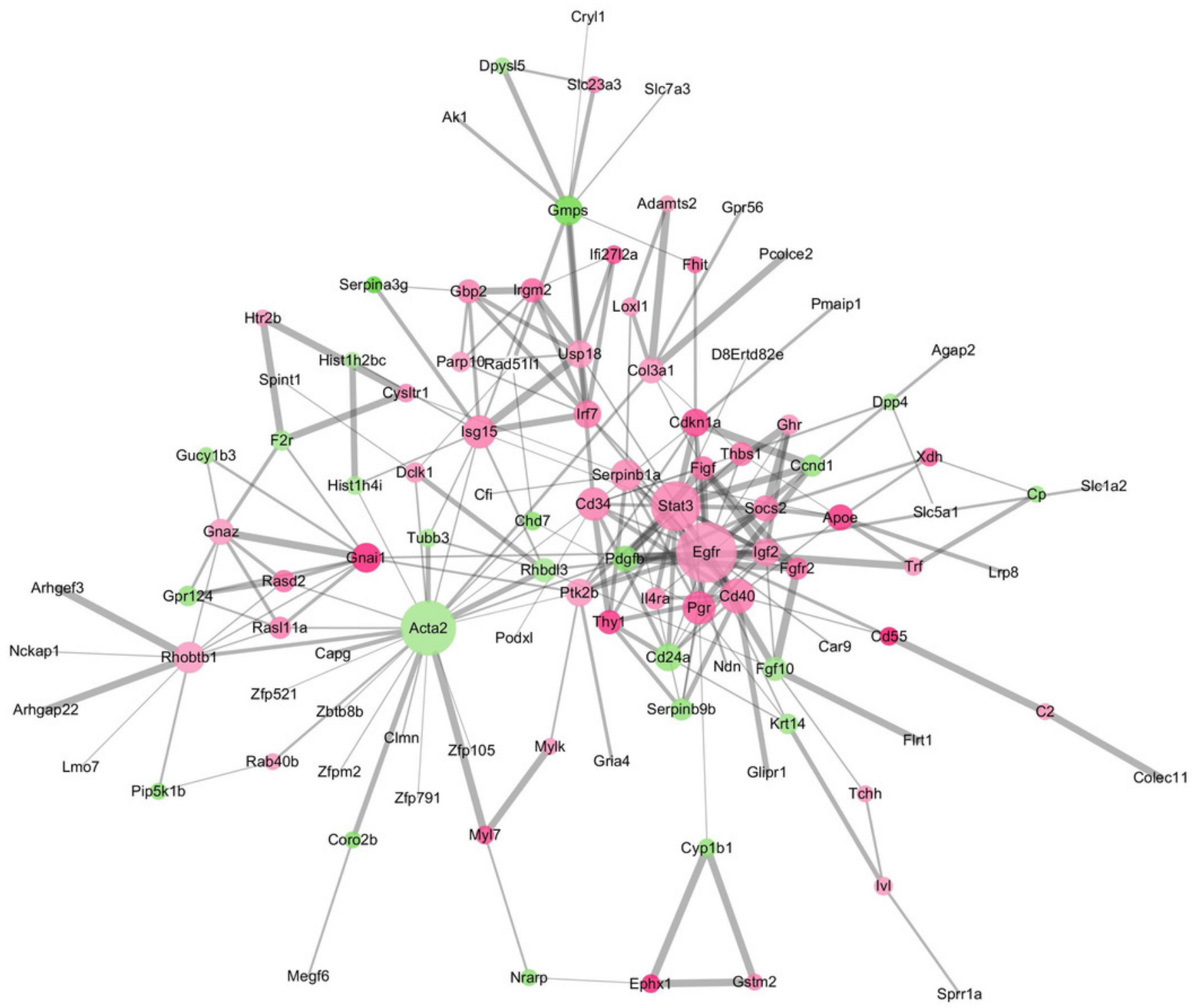




\section{Figure 5}

Identification and association of the top four-hub genes with survival of ovarian cancer patients.

A, The Oncoprint analysis to identify the four top hub genes. The cBioPortal represented the proportion and distribution of samples with alterations in hub genes. The graph is cropped to exclude samples without gene alterations or genetic alterations on the right. The red color indicates gene amplification, while the blue color represents gene deletion and the pink color gene up-regulation. B, The Kaplan-Meier curves of overall survival (OS) stratified by altered expression of these four genes. C, The Kaplan-Meier curves of disease-free survival (DFS) stratified by altered expression of these four genes.
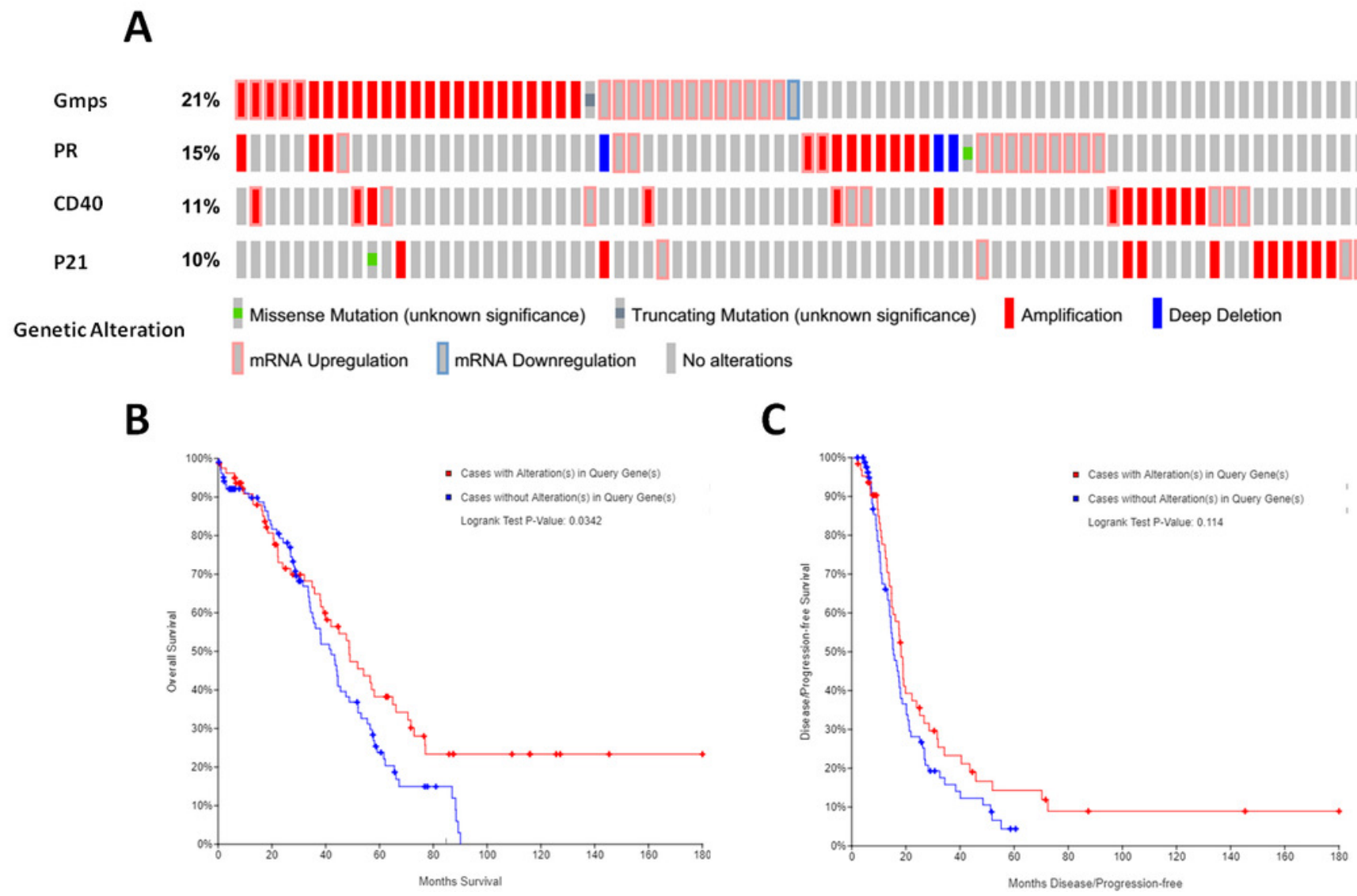
Figure 6

Differential GMPS, PR, CD40, and p21 expression between ovarian cancer and normal tissues and association with recurrence-free survival of ovarian cancer patients.

A-D, The Kaplan-Meier curves of recurrence-free survival (RFS) stratified by altered expression of these four genes. E-H, Differential expression of GMPS, PR, CD40, and p21 between ovarian cancer and normal tissues.
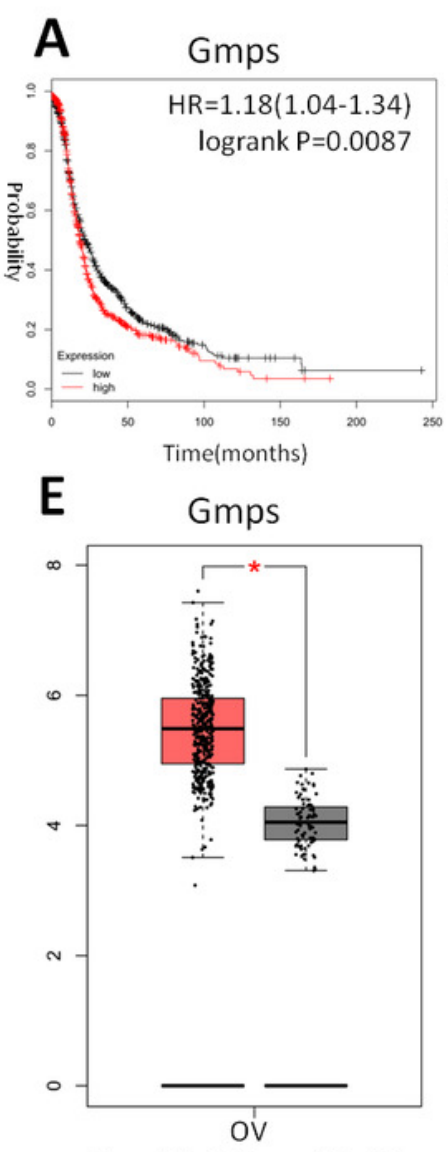

$\operatorname{Num}(T)=426 ; \operatorname{num}(N)=88$

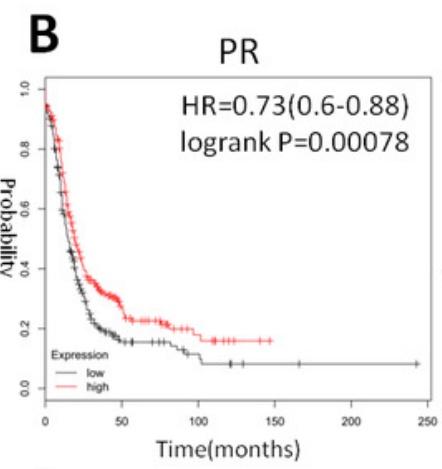

$\mathbf{F}$

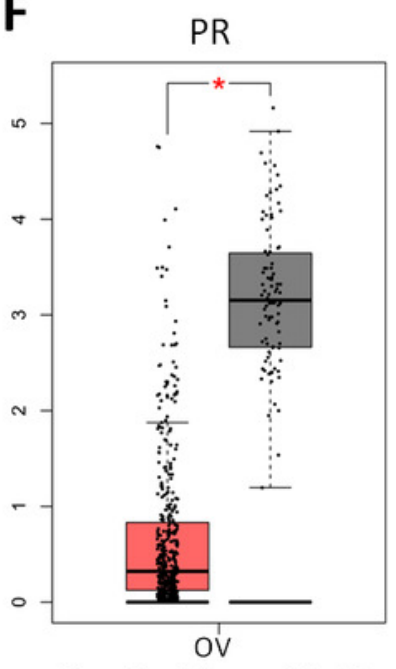

$\operatorname{Num}(T)=426 ; \operatorname{num}(N)=88$
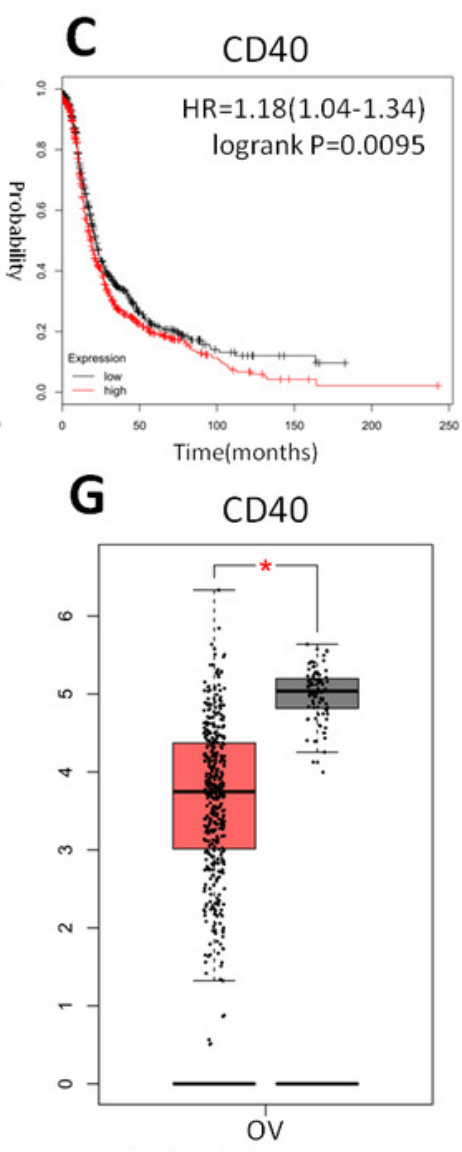

$\operatorname{Num}(T)=426 ; \operatorname{num}(N)=88$
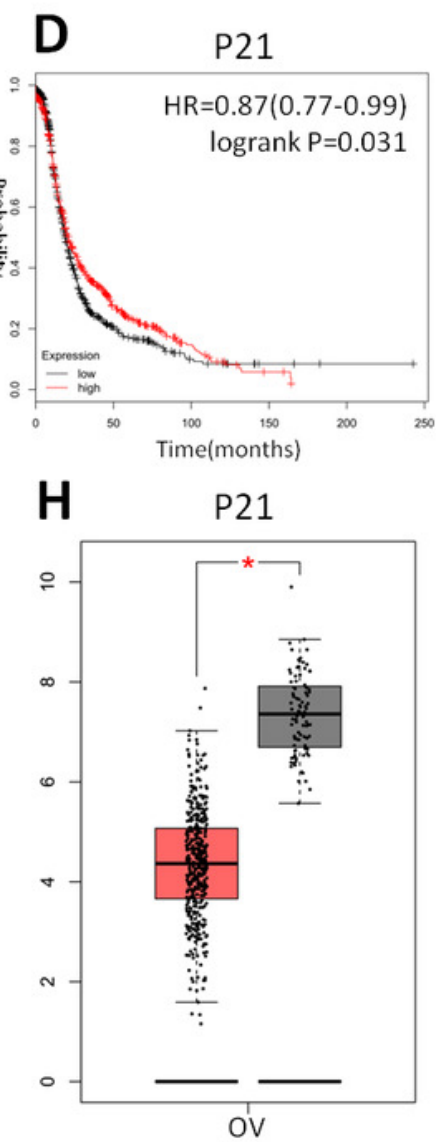

$\operatorname{Num}(T)=426 ; \operatorname{num}(N)=88$ 